\title{
Bilateral patellar tendon rupture on lupus undergoing corticosteroids: a case report
}

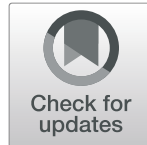

\author{
Zakaria El Ouali ${ }^{1 *}$ (D, Kawtar Nassar ${ }^{1}$, Elie Bassa ${ }^{1}$, Reda Taoussi ${ }^{2}$, Mouna Sabiri ${ }^{2}$, Mohamed Rafai ${ }^{3}$ and Saadia Janani ${ }^{1}$
}

\begin{abstract}
Background: Patellar tendon rupture is a rare condition, especially when it is bilateral. The most frequent associated pathologies are systemic lupus erythematosus, chronic renal failure, or treatments like corticosteroids. The aim of this case report is to draw attention to the non-specific clinical aspect of this condition, to recall its radiological signs, and highlight the diagnostic contribution of musculoskeletal ultrasound.

Case presentation: A 39-year-old man was diagnosed with a systemic lupus erythematosus with cutaneous, pulmonary, cardiac, hematological, renal, and immunological manifestations. He was treated with high-dose corticosteroids. Within 3 months he presented with a total functional impotence of the knees. On physical examination, there was a gap in the right infrapatellar region, his patellae were abnormally ascended, and his left knee was swollen. Insall-Salvati ratio on knees conventional radiographies was 2.5 in the right and 2.25 in the left knee, assessing bilateral patella alta. Ultrasound revealed a complete and bilateral patellar tendon rupture. The treatment consisted in a surgical repair and physiotherapy. The patient was able to mobilize independently after 6 months.
\end{abstract}

Conclusions: Bilateral patellar tendon rupture is exceptional. Systemic lupus erythematosus and corticosteroids are among trigger factors. Careful examination of the patellae should be done in front of knee extension deficit. Ultrasound plays a determining role in the diagnosis.

Keywords: Systemic lupus Erythematosus, Tendon rupture, Corticosteroids, Patella Alta, Ultrasound, Case report

\section{Background}

Patellar tendon rupture is a rare condition, tending to result from an overall weakened tendon placed under high tensile forces [1]. Known risk factors are inflammatory rheumatic and systemic diseases, diabetes mellitus, renal dialysis, and treatments like corticosteroids (CS) and fluoroquinolones (FQ) [1]. Simultaneous bilateral patellar tendon rupture (BPTR) is even more sporadically reported, making it more difficult to individualize its contributing factors [2]. We report a case of simultaneous BPTR in a 39-year-old man with SLE undergoing CS. Our purpose is to draw attention to the non-specific clinical aspects of this condition, to recall its radiological

\footnotetext{
*Correspondence: dr.elouali.zakaria@gmail.com

'Department of Rheumatology, University Hospital of Ibn Rochd, Casablanca (Morocco), 72 rue Abou Dabi, Oasis, 20410 Casablanca, Morocco

Full list of author information is available at the end of the article
}

signs, and to highlight the diagnostic contribution of musculoskeletal ultrasound (MSUS).

\section{Case presentation}

A 39-year-old man was diagnosed in March 2019 with a SLE following the criteria of the Systemic Lupus International Collaborating Clinics (SLICC), with multi-organ involvement. The cutaneous manifestations included a malar rash, nonscarring alopecia, photosensitivity, and a lupus strip on direct immunofluorescence taken from a skin biopsy. He had a proteinuria at $1.8 \mathrm{~g} / 24 \mathrm{~h}$, and the renal biopsy concluded in a lupus nephritis of classes 5 and 3 with an activity index of 1 . On the articular plan, he presented a chronic, non-deforming and non-destructive inflammatory polyarthritis. Hematologically, he had an autoimmune anemia (hemoglobin level $8.9 \mathrm{~g} / \mathrm{dL}$ with positive Coombs test), and a lymphopenia at $960 / \mathrm{mm} 3$.

(c) The Author(s). 2020 Open Access This article is licensed under a Creative Commons Attribution 4.0 International License, which permits use, sharing, adaptation, distribution and reproduction in any medium or format, as long as you give appropriate credit to the original author(s) and the source, provide a link to the Creative Commons licence, and indicate if changes were made. The images or other third party material in this article are included in the article's Creative Commons licence, unless indicated otherwise in a credit line to the material. If material is not included in the article's Creative Commons licence and your intended use is not permitted by statutory regulation or exceeds the permitted use, you will need to obtain permission directly from the copyright holder. To view a copy of this licence, visit http://creativecommons.org/licenses/by/4.0/ The Creative Commons Public Domain Dedication waiver (http://creativecommons.org/publicdomain/zero/1.0/) applies to the data made available in this article, unless otherwise stated in a credit line to the data. 
Immunologically, the anti-nuclear and native anti-DNA antibodies were positive, and the $\mathrm{C} 3$ fraction of the complement was low. He had polyserositis including pleural and pericardial effusions. Indicated treatments were highdose, long-term CS therapy $(1 \mathrm{mg} / \mathrm{kg} /$ day $)$ and hydroxychloroquine (HCQ), $400 \mathrm{mg} /$ day.

Two months after the start of treatment, the patient presented a painful buckling of both knees when walking, not responding to nonsteroidal anti-inflammatory drugs (NSAIDs). He developed total functional impotence 1 month later. When he consulted in our department, the patient was still on full-dose CS therapy, but had not started HCQ yet because he was scheduled for a complete ophthalmic check-up. He was unable to walk without crutches. The patellae were ascended, there was a gap in the right infrapatellar region, and the left knee was swollen (Fig. 1). Active knee extension was impossible.

The standard profile $\mathrm{x}$-ray showed bilateral patella alta (PA), with an Insall-Salvati ratio (ISR) of 2.25 in the right knee and 2.2 in the left (normal range 0.8-1.2) (Fig. 2). MSUS revealed a complete rupture of the two patellar tendons (Fig. 3). Magnetic resonance imaging (MRI), indicated before surgery, had an ISR of 1.87 on the right side and 1.88 on the left side (normal range $0.74-1.5$ ). The diastasis measured $40 \mathrm{~mm}$ on the right side and $45 \mathrm{~mm}$ on the left, filled on both sides with an effusion of great abundance (Fig. 4).

The patient was referred to trauma surgeons. The underlying SLE was stable: laboratory blood tests showed an erythrocyte sedimentation rate of $13 \mathrm{~mm}$, a C-reactive protein at $11.6 \mathrm{mg} / \mathrm{L}$ (normal $<5 \mathrm{mg} / \mathrm{L}$ ). The surgery consisted in a repair of the patellar tendons with sutures, associated with a reinforcement wire cerclage in

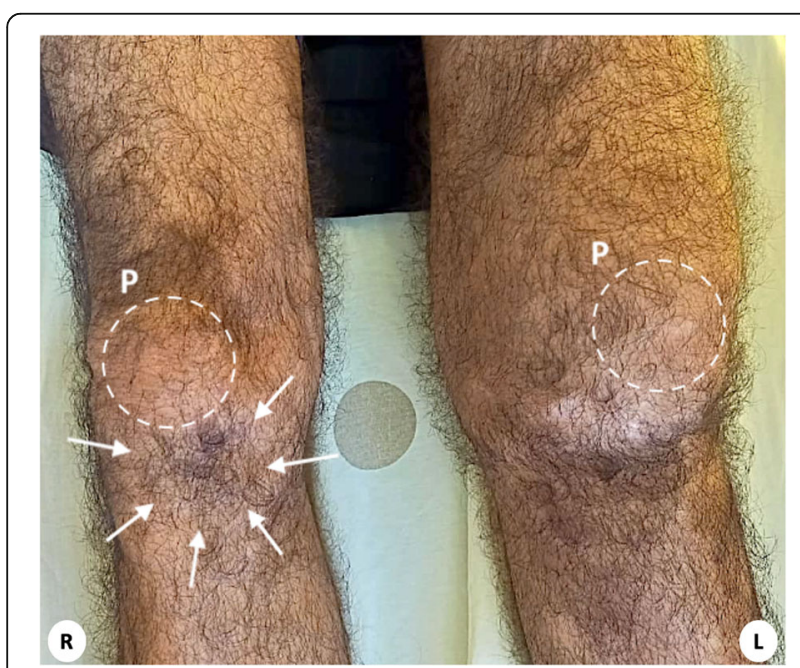

Fig. 1 Clinical aspect of the knees showing a gap in the right infrapatellar region (arrows), an ascension of both patellae (P), and a swollen left knee view of the poor tissue quality of the tendons. There were no postoperative complications. Physiotherapy was undertaken after immobilization by removable braces for 4 weeks. Sessions consisted in progressive extension/ flexion movements, and walking rehabilitation using a walking frame. After 2 weeks the patient was able to perform $80^{\circ}$ flexion of the right knee and $60^{\circ}$ of the left. He was dispensed with the walking frame, replaced by a single forearm crutch after 1 month of rehabilitation. The 3-month follow-up x-ray showed patellae in their normal position (Fig. 5, a and b). At 6 months postoperatively, the range of motion was $0^{\circ}-120^{\circ}$ of flexion in the right knee and $0^{\circ}-110^{\circ}$ in the left. He was able to mobilize independently. The SLE was stable under $15 \mathrm{mg} /$ day of CS and HCQ $400 \mathrm{mg} /$ day. The control MSUS showed the stability of the surgical repair (Fig. 5, c and d).

\section{Discussion and conclusion}

This is a case of BPTR in a patient with SLE, happening 2 months after the start of oral full-dose CS, and with a recovery of knee function after surgery and rehabilitation.

Tendon rupture usually is the result of underlying tendinosis or a weakened tendon by chronic inflammatory diseases, renal dialysis, patellar tendinopathy or previous injury [1]. Patellar tendon rupture is the third most frequent cause of disruption of the knee extensor mechanism after patella fractures and quadriceps tendon rupture [3], with an incidence of $0.5 \%$ in the United States [1]. BPTR is much rarer, with sporadic cases in the literature [4]. It has been reported in SLE [3], rheumatoid arthritis [5], chronic renal failure [6], and primary hyperparathyroidism [7]. Moreover, cases have been reported in apparently healthy people [8], and during sports activities [9]. Treatments like CS [10], FQ [11] and statins [12] also predispose to BPTR.

There are 3 categories of pathophysiological mechanisms being responsible for BPTR according to Taylor et al. [2]. First, the involvement of systemic or autoimmune diseases, causing inflammatory reactions, and weakening the tendon structure, resulting histologically in chronic inflammation and amyloid deposition. Second, the use of treatments such as oral or injectable CS, weakening the tendon by affecting the synthesis of collagen. Other incriminated treatments are $F Q$, which decrease fibroblasts proliferation [13], and statins, causing gross changes in the organization of collagen fibers and thinning of the epitenon [12]. The third pathophysiological category includes repeated microtraumas, causing degenerative tendon damage [2]. Our patient presented two of these risk factors: the underlying SLE, and the treatment with long-term CS.

In case of BPTR, both knees present symmetrical physical signs: swelling, ascending patellae with gaps in the infrapatellar regions. In our case, only the left knee 

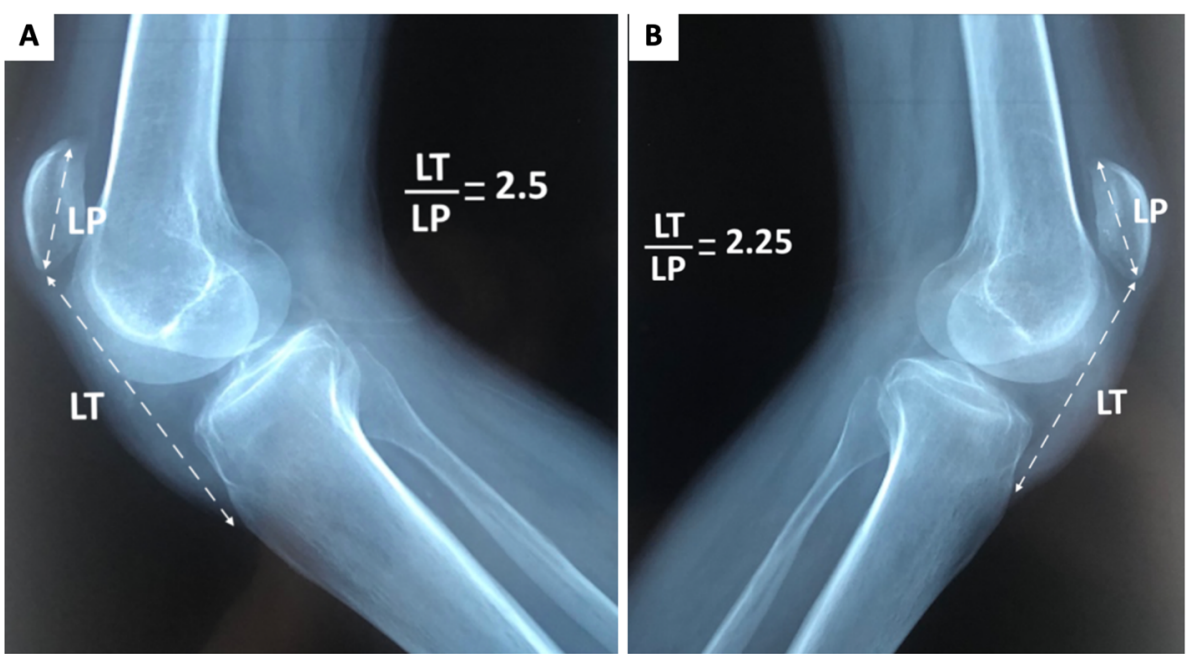

Fig. 2 Conventional radiography findings in both knees (a: right knee, $\mathbf{b}$ : left knee). Bilateral aspect of patella alta with the Insall-Salvati ratio. LP: length of the patella; LT: length of the patellar tendon

was swollen, and only the right knee had a visible gap. This difference could have led to a diagnosis delay for our patient, who was prescribed NSAIDs without improvement. Siwek and Rao reported that $28 \%$ of their BPTR patients were not diagnosed during their initial examination [14]. This highlights the non-specific clinical features of BPTR. Consequently, health care providers must be aware of this condition and of its risk factors in order to prevent diagnosis delay. Knee extension deficit should have the patellae carefully examined.

Radiologically, standard profile $\mathrm{x}$-rays on $30^{\circ}$ flexed knees aim to assess the aberrant high position of the patellae, called patella alta, which is quantified by the ISR [15]. It consists in calculating the ratio of the length of the patellar tendon (from the lower pole of the patella to its insertion on the tibia) over the patellar length (greatest pole-to-pole length). The normal range is 0.81.2 , and the diagnosis of PA is made if the ISR is greater than 1.2. In our patient, this ratio was 2.5 in the right knee and 2.25 in the left. Standard x-ray diagnoses PA, but does not specify its etiology, which is multiple: patellar tendon rupture, subluxation of the patella, SindingLarsen-Johansson disease, and joint effusion [16]. This highlights the interest of MSUS, which is a simple, easy to access, fast, and cost-effective imaging method of joint structures [16]. In case of a complete tendon rupture, the image is a total interruption of the normal fibrillar structure, with a continuity solution [16], which was found in our patient. MRI has an interest mainly for surgery: in addition to confirming the PA with a better assessment of the ISR, it provides more details about the topography and detects associated lesions.
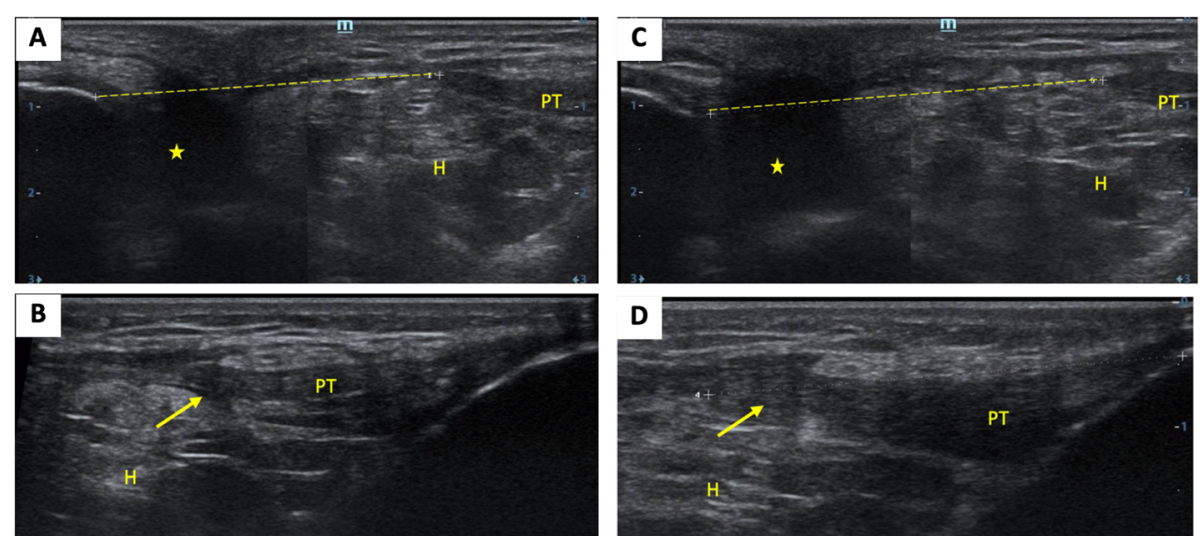

Fig. 3 Ultrasound of the knees performed using a high frequency linear transducer. $\mathbf{a}$ and $\mathbf{b}$ : right knee. $\mathbf{c}$ and $\mathbf{d}$ : left knee. Median sagittal sections of the patellar tendons (PT) showing the stump of the patellar tendon (arrow) and the diastasis between the apex of the patella and the stump (discontinuous line), associated with an effusion of the suprapatellar bursa (yellow star) as well as an infiltration of Hoffa's fat pad (H) 


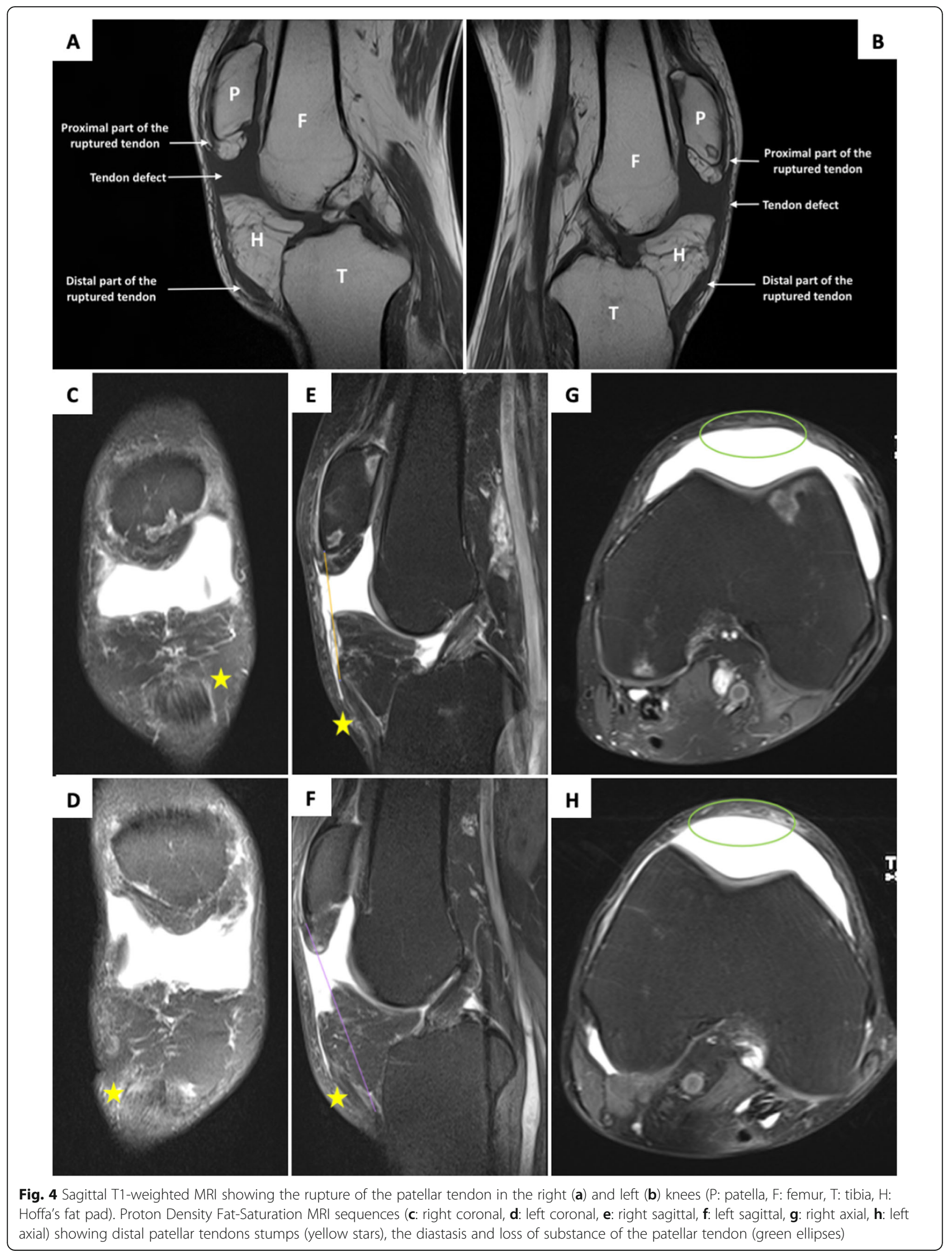



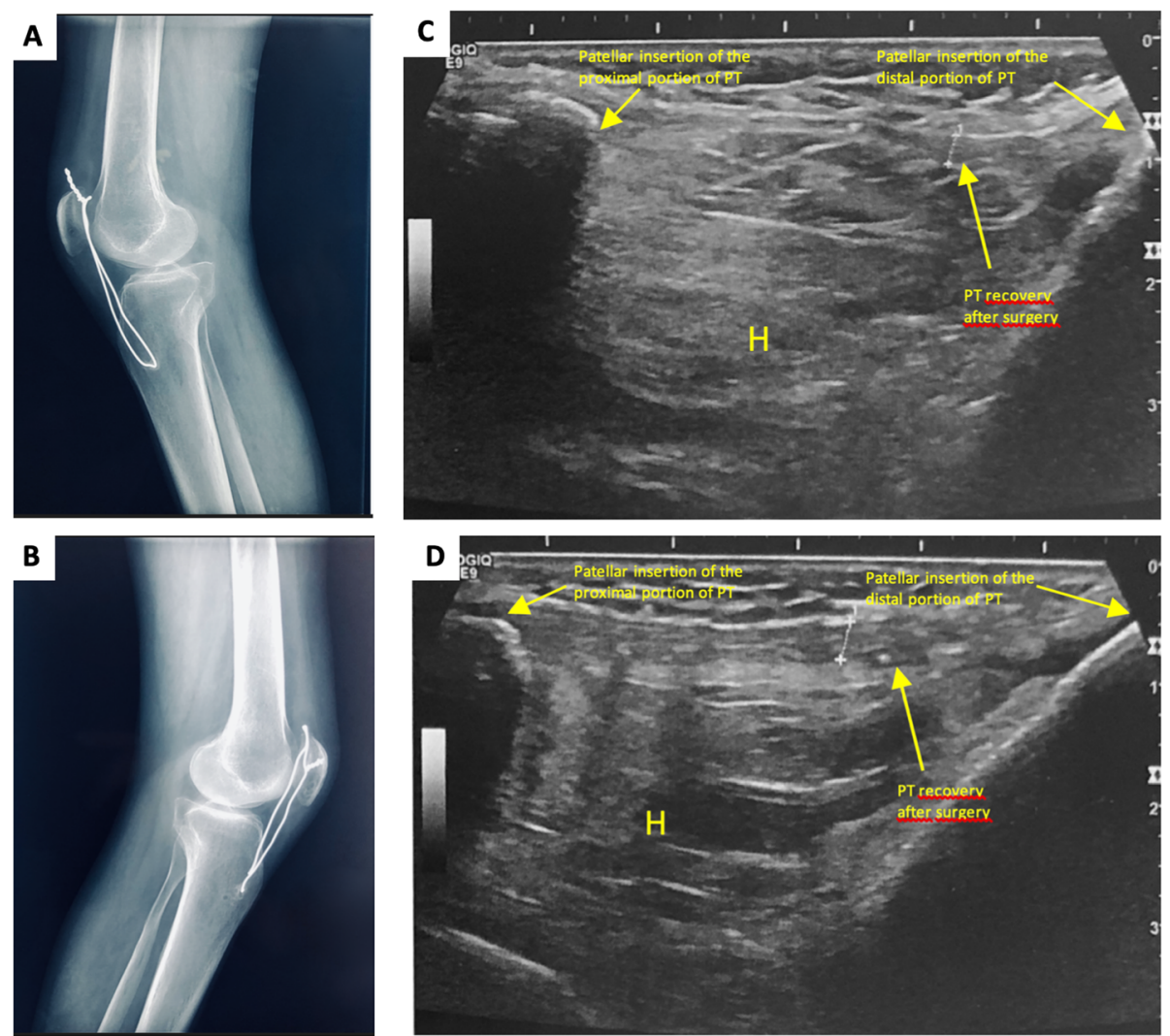

Fig. 5 Control $x$-rays at 3 months showing the recovery of the patellar height with the cerclage wires in the right (a) and left (b) knees. Ultrasound longitudinal scans of the knees at 6 months of follow-up showing recovered patellar tendons in the right (c) and left (d) knees. PT: patellar tendon, H: Hoffa's fat pad

The most often performed procedure is tendon repair by sutures on a healthy tendon [14]. In case of tendon fragility, the use of wire cerclage reduces the tension on the suture line and the risk of secondary rupture [17]. Our patient had an additional wire cerclage because the risk of secondary rupture is constant: chronicity of the SLE, and long-term CS therapy. Furthermore, Siwek and Rao insist on early diagnosis and prompt surgical repair to avoid tendon retraction and surgical failure [14].

In conclusion, BPTR is a rare complication of SLE and long-term CS therapy. The inflammatory reactions of the systemic disease, and the lack of collagen synthesis due to CS therapy, are among trigger factors. This condition should be suspected in a patient unable to perform active knee extension, and presenting bilateral PA. MSUS provides a rapid and reliable diagnosis. Early assessment and treatment give a better functional prognosis.

\section{Abbreviations}

BPTR: Bilateral patellar tendon rupture; CS: Corticosteroids;

FQ: Fluoroquinolones; HCQ: Hydroxychloroquine; ISR: Insall-Salvati ratio; MRI: Magnetic resonance imaging; MSUS: Musculoskeletal ultrasound; PA: Patella Alta; SLE: Systemic lupus erythematosus

\section{Acknowledgements}

We express our gratitude to Dr. Meriem Laanaya, MD, and Dr. Majdouline Badi, MD, who conducted ultrasound examinations for the patient in his initial assessment.

\section{Authors' contributions}

ZE: conception, data curation, interpretation, and writing of the manuscript. $\mathrm{KN}$, EB, and SJ: conception, data curation, and supervision of the draft. RT and MS: data curation and interpretation of the radiological figures of the article. MR: orthopedic surgeon, involved in data curation and interpretation. All the authors approved the submitted version of the manuscript.

\section{Funding}

Not applicable.

\section{Availability of data and materials}

Data concerning the patient's record are available from the corresponding author on reasonable request.

\section{Ethics approval and consent to participate}

The case report was approved by the Ethics Committee of the University Hospital of Ibn Rochd held on April 13th, 2020.

\section{Consent for publication}

Patient written consent was obtained.

\section{Competing interests}

The authors declare that they have no competing interests. 


\section{Author details}

'Department of Rheumatology, University Hospital of Ibn Rochd, Casablanca (Morocco), 72 rue Abou Dabi, Oasis, 20410 Casablanca, Morocco.

${ }^{2}$ Department of Central Radiology, University Hospital of Ibn Rochd,

Casablanca, Morocco. ${ }^{3}$ Department of Traumatology and Orthopedics P32,

University Hospital of Ibn Rochd, Casablanca, Morocco.

Received: 14 May 2020 Accepted: 15 July 2020

Published online: 21 July 2020

\section{References}

1. Hsu H, Siwiec RM. Patellar Tendon Rupture. In: StatPearls [Internet]: Treasure Island (FL): StatPearls Publishing; 2020. Available from: http://www.ncbi.nlm. nih.gov/books/NBK513275/. [cited 2020 Jun 16].

2. Taylor BC, Tancev A, Fowler T. Bilateral patellar tendon rupture at different sites without predisposing systemic disease or steroid use. lowa Orthop J. 2009;29:100-4.

3. Kellersmann R, Blattert TR, Weckbach A. Bilateral patellar tendon rupture without predisposing systemic disease or steroid use: a case report and review of the literature. Arch Orthop Trauma Surg. 2005;125(2):127-33.

4. Papanikolaou A. Charalambides, Thanassas. Spontaneous simultaneous bilateral patellar tendon rupture in a systemic lupus erythematosus patient. Lupus. 2007;16(11):915-7.

5. Peiró A, Ferrandis R, Garcia L, Alcazar E. Simultaneous and spontaneous bilateral rupture of the patellar tendon in rheumatoid arthritis: a case report. Acta Orthop Scand. 1975;46(4):700-3.

6. Caldas MTL, Barbara GHS, Bárbara MBF. Simultaneous bilateral rupture of the patellar ligament in chronic renal patient. A case report. Rev Bras Ortop (English Edition). 2013;48(5):455-9.

7. Chen $\mathrm{CH}$, Niu CC, Yang WE, Chen WJ, Shih CH. Spontaneous bilateral patellar tendon rupture in primary hyperparathyroidism. Orthopedics. 1999; 22(12):1177-9.

8. Sibley T, Algren DA, Ellison S. Bilateral patellar tendon ruptures without predisposing systemic disease or steroid use: a case report and review of the literature. Am J Emerg Med. 2012;30(1):261.e3-5.

9. Moura DL, Marques JP, Lucas FM, Fonseca FP. Simultaneous bilateral patellar tendon rupture. Rev Bras Ortop (English Edition). 2017:52(1):111-4.

10. Clark SC, Jones MW, Choudhury RR, Smith E. Bilateral patellar tendon rupture secondary to repeated local steroid injections. Emerg Med J. 1995: 12(4):300-1.

11. Rosa B, Campos P, Barros A, Karmali S, Gonçalves R. Spontaneous bilateral patellar tendon rupture: case report and review of fluoroquinolone-induced tendinopathy. Clin Case Rep. 2016;4(7):678-81.

12. Kearns MC, Singh VK. Bilateral patellar tendon rupture associated with statin use. J Surg Case Rep. 2016;2016(5):rjw072.

13. Stinner DJ, Orr JD, Hsu JR. Fluoroquinolone-associated bilateral patellar tendon rupture: a case report and review of the literature. Mil Med. 2010; 175(6):457-9.

14. Siwek CW, Rao JP. Ruptures of the extensor mechanism of the knee joint. J Bone Joint Surg Am. 1981;63(6):932-7.

15. Insall J, Salvati E. Patella position in the Normal knee joint. Radiology. 1971; 101(1):101-4.

16. Bartalena T, Rinaldi MF, De Luca C, Rimondi E. Patellar tendon rupture: radiologic and ultrasonographic findings. West J Emerg Med. 2010;11(1):90-1.

17. Larsen E, Lund PM. Ruptures of the Extensor Mechanism of the Knee Joint: Clinical Results and Patellofemoral Articulation. Clin Orthop Relat Res. 1986; NA(213):150-3.

\section{Publisher's Note}

Springer Nature remains neutral with regard to jurisdictional claims in published maps and institutional affiliations.

Ready to submit your research? Choose BMC and benefit from:

- fast, convenient online submission

- thorough peer review by experienced researchers in your field

- rapid publication on acceptance

- support for research data, including large and complex data types

- gold Open Access which fosters wider collaboration and increased citations

- maximum visibility for your research: over $100 \mathrm{M}$ website views per year

At $\mathrm{BMC}$, research is always in progress.

Learn more biomedcentral.com/submissions 